\title{
The medicalisation of female genital mutilation/cutting in Kenya: Perspectives of families and health care providers
}

Population Council

Follow this and additional works at: https://knowledgecommons.popcouncil.org/departments_sbsr-rh

Part of the Demography, Population, and Ecology Commons, Family, Life Course, and Society Commons, Gender and Sexuality Commons, and the International Public Health Commons How does access to this work benefit you? Let us know!

\section{Recommended Citation}

The medicalisation of female genital mutilation/cutting in Kenya: Perspectives of families and health care providers, Evidence to End FGM/C: Research to Help Girls and Women Thrive. New York: Population Council, 2019. 


\section{THE MEDICALISATION OF FEMALE GENITAL MUTILATION/CUTTING IN KENYA: PERSPECTIVES OF FAMILIES AND HEALTH CARE PROVIDERS}

The Evidence to End FGM/C programme consortium generates evidence to inform and influence investments, policies, and programs for ending female genital mutilation/ cutting in different contexts.

\section{Population Council} Lead Institution

Africa Coordination Centre for Abandonment of Female Genital Mutilation/Cutting, Kenya (ACCAF)

Global Research and Advocacy Group, Senegal (GRAG)

MannionDaniels Ltd. (MD)

Population Reference Bureau. (PRB)

University of Washington (Prof. Bettina Shell-

Duncan)

University of California, San Diego (Dr. Gerry Mackie)

\section{Funded by}

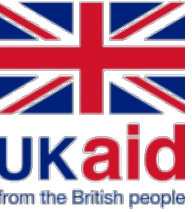

\section{INTRODUCTION}

About one out of every five women and girls aged $15-$ 49 years in Kenya ${ }^{1}$ has undergone female genital mutilation/cutting $(\mathrm{FGM} / \mathrm{C})$-a practice that is a violation of the rights of women and girls. The majority of women and girls in Kenya are cut by traditional practitioners, including traditional birth attendants (TBAs). However, girls are now increasingly being cut by health care providers-a practice known as the medicalisation of $\mathrm{FGM} / \mathrm{C}$ (Figure 1). ${ }^{1,2}$ Based on intergenerational data collected from mothers, daughters are less often cut by TBAs and other traditional circumcisers in comparison to their mothers.

Figure 1.Percentage of girls and women by who performed FGM/C, 2014 Kenya Demographic and Health Survey

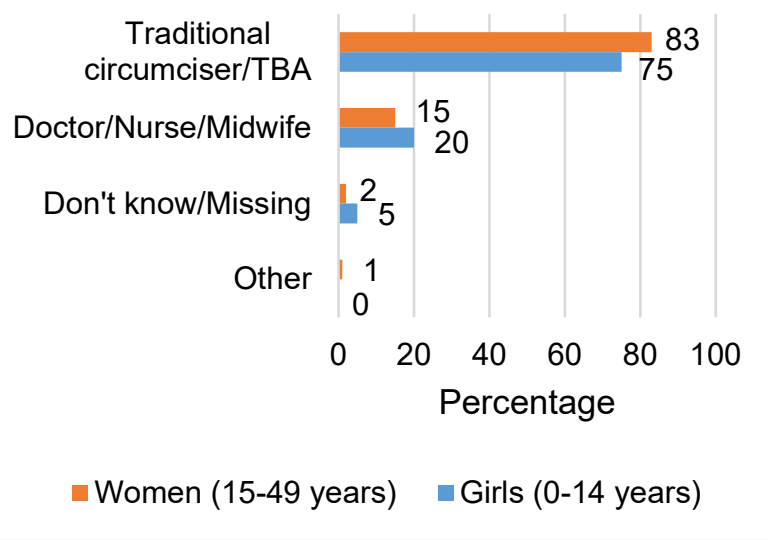

Medicalised FGM/C is carried out in hospitals, at home, or at neutral places using surgical tools, antiseptics, and anaesthetics. ${ }^{2}$ Some of the reasons for medicalisation of $\mathrm{FGM} / \mathrm{C}$ include the reduction of immediate complications while allowing the women and girls to adhere to their cultural obligations, and financial benefits for the practitioners. ${ }^{2-5}$ Medicalisation of $\mathrm{FGM} / \mathrm{C}$ has been documented among the Kisii and Somali communities in Kenya. ${ }^{3,4}$

This evidence brief summarises key findings from a study ${ }^{6}$ that sought to understand the shifts in FGM/C including medicalisation among the Kisii, Kuria, and Somali communities in Garissa, Kisii, Migori, and Nairobi counties.

\section{Recommendations}

- Awareness raising programmes should clarify that the medicalisation of FGM/C is detrimental to the health of women and girls.

- Health care providers should be trained on the complications associated with $\mathrm{FGM} / \mathrm{C}$ as well as legal and human rights issues. This training should also address their role in the abandonment of the practice.

- Health professionals' associations and health regulatory agencies should have clear guidelines and standards for providers that outline the sanctions against those who perform FGM/C. 


\section{METHODS}

Data were collected using qualitative methods: key informant interviews (KIIs), in-depth interviews (IDIs), and focus group discussions (FGDs). Klls were held with administrative, religious, and community leaders, as well as health sector stakeholders in each region. The IDIs and FGDs were conducted among women of reproductive age, young mothers, older women, young fathers, older men, and girls.

\section{FINDINGS}

\section{Where is medicalised FGM/C taking place?}

Medicalisation was noted to be common among the Abagusii and Somali communities. Medicalised FGM/C occurred in both urban and rural areas but was noted to be more common in urban areas. Although some girls were cut in private health facilities, having the health care provider perform the cut at home enabled families to keep the event secret.

Medicalised FGM/C was rarely reported by participants in Kuria. The community appears to be stable, consistent, and resistant to the shift of medicalisation. The council of elders, who are custodians of the Kuria culture, were noted to play a central role in selecting cutters, which might explain why girls in the Kuria community are primarily subjected to traditional cutting.

\section{"Medicalised FGM/C. No, that one I have never heard about it in our community. It's like a taboo for a girl to be circumcised in hospital."}

Female, Religious leader, Kuria

\section{Why is medicalisation increasing?}

- It is perceived to be safer because the procedure, is reportedly performed under sterile conditions by trained health professionals.

- Medicalisation is believed to shorten the recovery period.

- It is a response to the law prohibiting the practice because it allows $\mathrm{FGM} / \mathrm{C}$ to be performed in secret.

\section{"Medicalised FGM/C allows families to cut} and hide their girls because they do not stay for long while recuperating in the house. For the medicalised $F G M / C$, no one will even know a girl have been cut." 40-year-old woman, Nairobi
Why do health care providers perform FGM/C?

As illustrated in Figure 2, health care providers' motives for performing FGM/C centred around three issues: a desire to reduce the negative impacts of the practice; a fear of negative sanctions from the community if they refuse to perform FGM/C; and medicalised FGM/C boosts health care providers' income.

Figure 2. Reasons why health care providers perform FGM/C

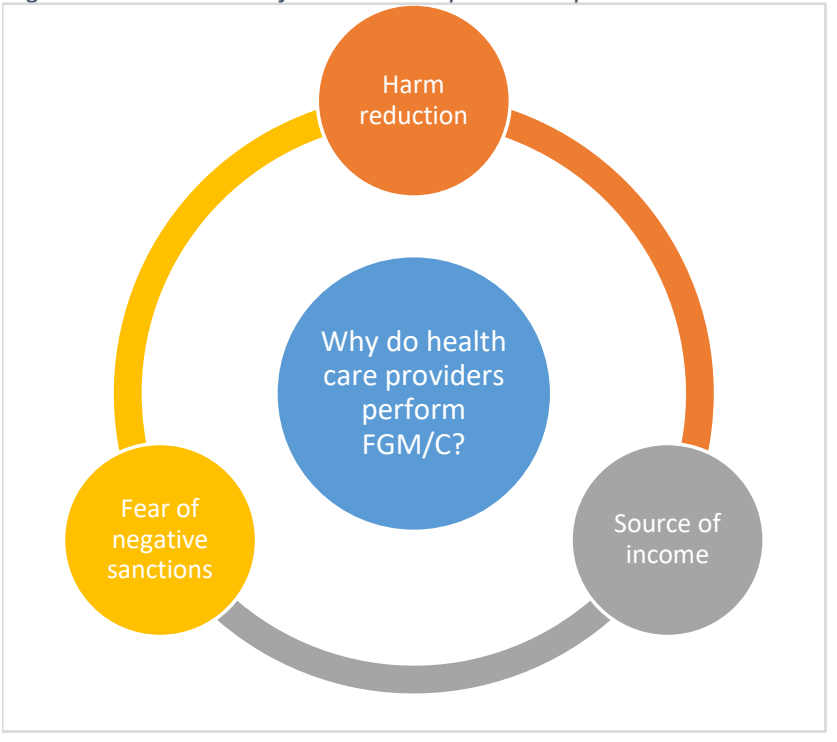

\section{CONCLUSION}

Study findings suggest that medicalisation is an adaptation to awareness of health complications associated with $\mathrm{FGM} / \mathrm{C}$ and the legal banning of the practice. These results underscore the need for antiFGM/C programmes that target health care providers.

\section{REFERENCES}

1. KNBS, \& ICF International. (2014). Kenya Demographic and Health Survey 2014. Calverton, Maryland: KNBS \& ICF International.

2. Kimani S, Shell-Duncan B. (2018). Medicalized female genital mutilation/cutting: contentious practices and persistent debates. Current Sexual Health Reports. 10:25-34.

3. Jaldesa, G. W., Askew, I., Njue, C., and Wanjiru, M. (2005). Female genital cutting among the Somali of Kenya and management of its complications. https://bit.ly/2FOVstw

4. Njue, C., and Askew, I. (2004). Medicalisation of female genital cutting among the Abagusii in Nyanza Province, Kenya. Frontiers in Reproductive Health. New York: Population Council

5. UNICEF. (2013). Female genital mutilation/cutting: a statistical overview and exploration of the dynamics of change. New York: UNICEF.

6. Kimani, S and Kabiru, C W. (2018). Shifts in female genital mutilation/cutting in Kenya: Perspectives of families and health care providers. Evidence to End FGM/C: Research to Help Girls and Women Thrive. New York: Population Council. 